\title{
Effects of Moringa oleifera Leaf Powder as Feed Additives on Growth Performance and Blood Parameters of Broiler
}

\author{
Naqash Khalid ${ }^{1 *}$, Syeda Faryal Sakhawat ${ }^{2}$, Hajira Mehmood ${ }^{2}$, Malik Mohsin Ali ${ }^{1}$, Riaz Ali ${ }^{1}$, \\ Yasir Amin ${ }^{1}$, Muhammad Ayaz ${ }^{1}$
}

\section{${ }^{1}$ Poultry Research Institute Jaba, Khyber Pakbtunkbwa, Pakistan; ${ }^{2}$ Department of Zoology, Hazara University Mansehra, Khyber Pakbtunkbwa, Pakistan.}

\begin{abstract}
The current experiment was designed to investigate the impact of Moringa Leaf Powder as feed additives on growth performance and blood parameters of broilers. For this purpose, total of $240 \mathrm{DOC}(\mathrm{Cobb}-500)$ were purchased from the local market. On day of arrival at the farm, chicks were weighed and were divided equally into 4 experimental groups group A, group B, group C and group D having 3 replicas each containing 20 chicks in each replica. Standard feeding and managemental conditions were given to the chicks throughout the experimental period. Group A was considered as control group (no treatment). Group B, C and D were supplemented the Moringa leaf powder with the percentage of $0.5 \%, 0.1 \%$ and $0.15 \%$, respectively. From the obtained results, it was found that the broilers in the group $\mathrm{D}$ were had higher weight gain and FCR $(\mathrm{p}<0.05)$ as compared to group A, B and C. Furthermore, the H:L of group $\mathrm{D}$ was also lowest $(\mathrm{p}<0.05)$ (minimum oxidative stress) as compared to group A, B and C. Hence it was concluded that Moringa leaf powder supplemented with the dose of $0.15 \%$ had best effect on productive performance and hematology of the broilers. On the basis of results of current study it was concluded that MOLP supplementation in feed had best effects on the productive performance of the broilers. It was also concluded that MOLP had no effect on the mortality of the broilers.
\end{abstract}

Keywords | Moringa, Broiler, Growth Performance, Blood Parameters, Feed Intake and FCR.

Received | May 15, 2021; Accepted | June 19, 2021; Published | July 15, 2021

*Correspondence | Naqash Khalid, Poultry Research Institute Jaba, Khyber Pakhtunkhwa, Pakistan; Email: dr.naqash092@gmail.com

Citation | Khalid N, Sakhawat SF, Mehmood H, Ali MM, Ali R, Amin Y, Ayaz M (2021). Effects of moringa oleifera leaf powder as feed additives on growth performance and blood parameters of broiler. J. Anim. Health Prod. 9(3): 271-276.

DOI | http://dx.doi.org/10.17582/journal.jahp/2021/9.3.271.276

ISSN | 2308-2801

Copyright (C) 2021 Khalid et al. This is an open access article distributed under the Creative Commons Attribution License, which permits unrestricted use, distribution, and reproduction in any medium, provided the original work is properly cited.

\section{INTRODUCTION}

$\mathrm{M}$ oringa is a flowering plant of family Moringaceae and is a sole genus of its flowering plant family. Its habitat is tropical and sub-tropical climates and genus of Moringa had 13 species. Moringa oleifera tree has its beneficial properties from its leaves to roots (Yang et al., 2006). Composition of dried leaves of the Moringa oleifera comprise of $25.1 \%$ crude protein, $11 \%$ ah contents, $5.4 \%$ lipids, $11.4 \%$ acidic detergent fiber and $21.9 \%$ neutral detergent fiber. Moringa oleifera also contains $44.4 \%$ carbohydrates (Nkukwana, 2012; Teixeira et al., 2014). For enhancing the gut health in poultry industry, Antibiotic Growth Promoters (AGP) has been used as the feed additives to control the sub-clinical diseases. This use had increases the bacterial resistance to the antibiotics, which increases the public concerns, which results in limited or eliminated the use of AGP in many countries (Fathallah et al., 2020). Consequently, alternatives to AGP was essential to be suggested to livestock producers in order to keep carcass quality, productivity and animal health (Yang et al., 2006).

Pterygospermin is a compound originates in flowers and roots of the Moringa have powerful fungicidal and antibiotic effects. Moringine and moringinine are the two alkaloids present in the root bark. For regulating the thyroid hormone and to treat the hyperthyroidism, aqueous leaf extracts are being used. Ulcer may also be treated by 
leaf extracts. Moringa is used for improving the intestinal health of the chickens and enhance immune response of the poultry Anti-tumor promoting activity and blood cholesterol had also reported to be effected by the pods and Moringa leaves (David et al., 2012). The use of Moringa oleifera specially its dehydrated leaves in broilers chicken considerably improves immune response, increased Lactobacillus counts in the ileum and reduced the Escherichia coli (E. coli). Therefore, it is cleared that Moringa has a great potential to support the immune functions and improving nutrition of the broiler chickens (Yang et al., 2006). Moringa Oleifera Leaf Powder (MOLP) contains the elevated amount of vitamin $C$ which is $22 \mathrm{mg} / 10 \mathrm{mg}$ the might produce resistance against infectious diseases and provide the improved immunity in both the cold and hot climatic circumstances (Gowrishankar et al., 2010).

A natural source of protein with great potential is Moringa oleifera, which apart from its medical uses is a good source of vitamins and amino acids. The utilization of chips could solve the problem of dustiness while some of the nutritional deficiencies could be alleviated with Moringa inclusion thereby enhancing the utilization of cassava and the easy adoption by the common poultry farmer (Olugbemi, et al., 2010). Moringa oleifera promotes growth performance of broilers by effecting gut-associated immune components and gut architectural integrity (Khan et al., 2017). Moringa Oleifera Leaf Powder (MOLP), can be used in broiler's diet, considering the potential nutrients in the plant, considered as the replacement of feed additives. Reports are present on MOLP supplementation in the broiler's diet increases the growth performance and immune response of the broilers (Onu \& Aniebo, 2011). Moringa oleifera leaf meal was replaced for sunflower seed meal as source of the protein for the layers. The effects of substitution on weight gain, feed intake, feed conversion ratio, dry matter intake and laying percentage were investigated and found that Moringa leaves could completely replace SSM up to $20 \%$ without detrimental effect on layers. However the crude fiber content if high can impair nutrient digestion and absorption (Banjo, 2012).

From the literature cited above, it was cleared that the MOLP had beneficial effects on the growth performance and blood parameters of the broilers. Therefore the current experiment was designed to examine the effects of MOLP as feed additive on productive performance and hematology of the broilers on high altitude.

\section{MATERIAL AND METHODS}

\section{Area of The Study}

The current study was executed at the poultry research institute Jaba, located in District Mansehra. District Mansehra is located in high altitude of Khyber Pakhtunkhwa province. Elevation of the District is $1088 \mathrm{~m}$ from the sea level. Short summer season in the District makes it suitable and economical for the Poultry Production (Amber et al., 2019).

\section{Management of the Birds}

A total of 240 day old chicks (Cobb-500) were purchased from the local hatchery. Chicks were weighed on day of arrival in the broiler house and were equally distributed, into the partitions having fresh rice husk litter in the conventional broiler house which was similar to the commercial standards. Chicks were distributed equally in 4 groups that were group $\mathrm{A}$, group $\mathrm{B}$, group $\mathrm{C}$ and group $\mathrm{D}$ having 3 replicas each group containing 20 chicks in each replica. Standard feeding and managemental conditions were given to the chicks throughout the experimental period. Chicks were vaccinated according to the protocol given in the broiler Cobb-500 manual. To prepare Moringa leaf powder, undamaged mature and fresh green Moringa leaves were used. The leaves were dried in shady area. The leaves were crushed after drying, to make fine powder. This powder was supplemented in the feed of the broilers with the ratio of $0.05 \%, 0.1 \%$ and $0.15 \%$ in group $\mathrm{B}, \mathrm{C}$ and $\mathrm{D}$ respectively from day $1^{\text {st }}$ to day $35^{\text {th }}$ of experimental period. Group A was considered as control group and was received normal basal diet without any supplementation. Ingredients in the basal diets were recorded and given in the Table 1.

Table 1: Basal Diet formulation for broilers

\begin{tabular}{|llll|} 
S. No & Ingredients & Starter & Finisher \\
\hline Maize $(\mathrm{g} / 100 \mathrm{~g})$ & 18 & 41.91 \\
\hline Rice broken $(\mathrm{g} / 100 \mathrm{~g})$ & 43.41 & 30 \\
\hline Rice polish $(\mathrm{g} / 100 \mathrm{~g})$ & 4.22 & 3.29 \\
\hline Sunflower meal $(\mathrm{g} / 100 \mathrm{~g})$ & 5 & 3 \\
\hline Canola meal $(\mathrm{g} / 100 \mathrm{~g})$ & 7 & 5 \\
\hline Guar meal $(\mathrm{g} / 100 \mathrm{~g})$ & 6 & 4 \\
\hline Corn Gluten $30 \%(\mathrm{~g} / 100 \mathrm{~g})$ & 2 & 1 \\
\hline Corn Gluten $60 \%(\mathrm{~g} / 100 \mathrm{~g})$ & 3 & 3.5 \\
\hline Fish meal $(\mathrm{g} / 100 \mathrm{~g})$ & 9 & 8 \\
\hline Premix $(\mathrm{g} / 100 \mathrm{~g})$ & 0.37 & 0.30 \\
\hline
\end{tabular}

\section{Data Collection}

Feed consumption of the broilers and their average body weight gain was recorded at weekly intervals, compiled and compared on the completion of the experiment. By using the feed consumption and body weight gain, feed conversion ratio (FCR) was calculated for each group. Mortality was recorded separately for each group. Blood samples were collected from 3 chicks per group through wing vein on the $35^{\text {th }}$ day of the experiment. These samples were col- 
lected into clean, plastic Vacutainer tubes (BD, Germany) containing anticoagulant Ethylenediaminetetraacetic acid (EDTA). Blood smears were prepared with anticoagulant blood to minimize degenerative changes in the blood cells. Differential Leukocyte Count (DLC) was performed at the Poultry Research Institute (PRI) Jaba, Mansehra. For DLC, take a clean microscope glass slide and smeared one drop of fresh blood about of about $2 \mathrm{~mm}$ in diameter on the slide. One more slide was used as the spreader and was placed for spreading the blood at 40 degree angle to the first slide and was make a thin film of $2-3 \mathrm{~cm}$ in length. This smear was left for the drying. Methyl alcohol was used as fixative agent for 2 minutes and the Giemsa stain was used for dilution, diluted at 1:9 with buffer over the smear for 2-3 minutes (Ceciliani et al., 2020). Wash off with buffer, dry it and was observed without cover slip. Heterophils and lymphocytes cells were calculated in 100 cells per field, and their ratio was calculated.

\section{Ethical Approval of the Study}

The study was approved by the Director General (Research) Livestock and Dairy Development Department (LR\&DD) Khyber Pakhtunkhwa, Peshawar. Ethical approval was taken by Director General LR\&DD Khyber Pakhtunkhwa, Peshawar and Director Poultry Research Institute Jaba, Mansehra for publishing the results.

\section{Statistical Analysis}

The obtained data was tabulated and compiled in the excel worksheet. For the difference among the groups, SPSS software was used in which Complete Randomized Design (CRD) was applied and probability value was taken at the $p<0.05$ (Nopiya, Hindriana, \& Sulistyono, 2020).

\section{RESULTS}

\section{Productive Performance of the Broilers}

The highest feed intake (FI) was recorded in control group $(3090 \pm 12 \mathrm{~g})$ followed by group of broilers supplemented with $0.1 \%$ MOLP $(3075 \pm 12 \mathrm{~g}), 0.05 \% \operatorname{MOLP}(3066 \pm 11 \mathrm{~g})$ and minimum FI $(3058 \pm 13 \mathrm{~g})$ was recorded in the group of broilers supplemented with $0.15 \%$ MOLP. There was found a significant ( $p>0.05)$ difference in FI between the selected 4 groups of the experiment as shown in the table 2. Weight gain of the broilers supplemented with $0.15 \%$ MOLP was highest $(2115 \pm 11)$ followed by the group of broilers supplemented with 0.1\% MOLP $(2072 \pm 9), 0.05 \%$ MOLP (2018 \pm 10$)$ and minimum weight gain was recorded in the control group of broilers $(1850 \pm 9)$. There found a significant $(\mathrm{p}<0.05)$ difference found in the weight gain of the broilers in 4 selected groups as shown in the table 2. The group of broilers supplemented with $0.15 \%$ MOLP had best FCR (1.42 \pm 0.04$)$ followed by the group of broilers supplemented with 0.1\% MOLP (1.46 \pm 0.03$), 0.05 \%$
MOLP $(1.52 \pm 0.02)$ and poor FCR was recorded in the control group of boilers as compared to the broilers of the groups supplemented with MOLP. There was a significant difference $(p<0.05)$ found in the FCR of the broilers of 4 selected groups as shown in the Table 2 .

Table 2: Productive performance of the broilers supplemented with MOLP

\begin{tabular}{|llll} 
& $\begin{array}{l}\text { Feed Intake } \\
(\mathbf{g})\end{array}$ & $\begin{array}{l}\text { Weight Gain } \\
(\mathbf{g})\end{array}$ & FCR \\
\hline MOLP 0\% & $3090 \pm 12$ & $1850 \pm 9$ & $1.67 \pm 0.03$ \\
\hline MOLP 0.05\% & $3075 \pm 11$ & $2018 \pm 10$ & $1.52 \pm 0.02$ \\
\hline MOLP 0.1\% & $3066 \pm 12$ & $2072 \pm 9$ & $1.48 \pm 0.03$ \\
\hline MOLP 0.15\% & $3058 \pm 13$ & $2115 \pm 11$ & $1.44 \pm 0.04$ \\
\hline P-Value & $<0.05$ & $<0.05$ & $<0.05$ \\
\hline
\end{tabular}

MOLP $0 \%=$ Control group having no treatment.

MOLP $0.05 \%=0.5 \%$ Supplementation of Moringa Oleifera Leaf Powder in feed.

MOLP $0.1 \%=1 \%$ Supplementation of Moringa Oleifera Leaf Powder in feed.

MOLP $0.15 \%=1.5 \%$ Supplementation of Moringa Oleifera Leaf Powder in feed.

No Mortality was found in the broilers during the experimental period in all the groups included in the experiment.

Differential Leukocytes Count of THE Broilers Heterophils count was recorded highest $(33 \pm 2 \%)$ in the group of broilers supplemented with $0.15 \%$ MOLP followed by MOLP $0.05 \%(32 \pm 2 \%)$ and MOLP $0.1 \%$ $(32 \pm 2 \%)$ and minimum Heterophils count $(32 \pm 2 \%)$ was found in the control groups of the broilers. There was a significant $(p<0.05)$ difference found in Heterophils count of broilers of all the selected groups as shown in the Table 3. Lymphocytes count was found highest $(53 \pm 3 \%)$ in the control group of the broilers followed by the broilers supplemented with $0.1 \%$ MOLP $(52 \pm 3 \%)$ and $0.05 \%$ MOLP $(52 \pm 3 \%)$ and minimum Lymphocytes count was found in the group of broilers supplemented with 0.15\% MOLP. There was a significant difference $(p<0.05)$ found in the Lymphocytes count of all the selected groups of broilers as shown in the Table 3. Heterophils to Lymphocytes Ratio $(\mathrm{H}: \mathrm{L})$ was lowest in the control group of broilers followed by the group of broilers supplemented with MOLP $0.1 \%$ (0.61 \pm 0.2$)$, MOLP $0.05 \%(0.61 \pm 0.2)$ and highest $\mathrm{H}: \mathrm{L}$ was recorded in the group of broilers supplemented with $0.15 \%$ MOLP. There was a significant difference found in H:L between all the selected groups of the broilers as shown in the Table 3. 
OPEN OACCESS

Table 3: Differential Leukocytes count (\%) of the broilers supplemented with MOLP

\begin{tabular}{llll} 
& $\begin{array}{l}\text { Heterophils } \\
\text { Count \% }\end{array}$ & $\begin{array}{l}\text { Lymphocytes } \\
\text { Count \% }\end{array}$ & H:L \\
\hline MOLP 0\% & $31 \pm 2$ & $53 \pm 3$ & $0.58 \pm 0.1$ \\
\hline MOLP 0.05\% & $32 \pm 2$ & $52 \pm 3$ & $0.61 \pm 0.2$ \\
\hline MOLP 0.1\% & $32 \pm 2$ & $52 \pm 3$ & $0.61 \pm 0.2$ \\
MOLP 0.15\% & $33 \pm 2$ & $51 \pm 3$ & $0.64 \pm 0.2$ \\
P-Value & $<0.05$ & $<0.05$ & $<0.05$
\end{tabular}

$\mathrm{H}: \mathrm{L}=$ Heterophils to Lymphocytes Ratio.

MOLP 0\%= Control group having no treatment.

MOLP $0.05 \%=0.5 \%$ Supplementation of Moringa Oleifera Leaf Powder in feed.

MOLP $0.1 \%=1 \%$ Supplementation of Moringa Oleifera Leaf Powder in feed.

MOLP $0.15 \%=1.5 \%$ Supplementation of Moringa Oleifera Leaf Powder in feed.

\section{DISCUSSION}

Moringa Oleifera Leaf Powder (MOLP) was used as supplement in the feed of the broilers for enhancing the productivity of the broilers in context to the study conducted by (Abbas, 2013) in which they stated that due to the high immunomodulatory, nutritional and antimicrobial properties of Moringa Oleifera leaves, have been reported to be used as dietary supplement for poultry and published advanced articles (Khan et al., 2017). In the current study, feed Intake of the broilers was recoded maximum in the control group of broilers and was found minimum in the broilers supplemented with $0.15 \%$ MOLP and there found not a remarkable difference found in the feed intake of the broilers with different treatments as compared with the control group broilers. These results had an agreement with the results of (Olugbemi et al., 2010) in which they stated that although efficiency of feed utilization decreased with increased levels of Moringa Oleifera Leaf Meal (MOLM), there were no significant differences in feed intake recorded between birds on most of the treatments. This observation was also supported by the findings of (Ravindran, Kornegay, \& Cherry, 1983) in which feed intake and feed/gain increased as cassava leaf meal or dehydrated alfalfa meal leaf meals incorporated level was increased. The cheapest feed cost /weight gain were from diets 5 and 2 representing the 30 and 20\% cassava groups but did not differ significantly ( $p>0.05)$ from diets 1,3 and 6 . In the results, the group of broilers supplemented with $6 \%$ Moringa oleifera leaf powder and $2 \%$ canola meal consumed maximum feed when compared with the other group of broilers included in the study (Liaqat et al., 2016). According to another research, it was reported that feed intake of broilers might be stimulated by the presence of alkaloid of Moringa through their influence on homeostasis of glucose in the broilers (Mbikay, 2012).
Total weight gain in the current study was found maximum in the group of broilers supplemented with $0.15 \%$ MOLP and minimum weight gain was found in the control group of broilers. Feed efficiency or Feed Conversion Ratio (FCR) was found best in the group of broilers supplemented with $0.15 \%$ MOLP as compared to the other different level of supplementations and also from the control group of broilers present in the study. There was a significant $(p<0.05)$ difference found in weight gain and FCR of the broilers. This might be suggestive of the fact that this dose of MOLP may have growth promoting and improving feed efficiency properties. These results were correlated with the findings of (Khan et al., 2017) in which they found a significant increase in the final body weight of the broilers supplemented with the different levels of MOLP. The broilers present in the group supplemented with $1.2 \%$ MOLP had highest weight gain throughout the experiment. Another study conducted by (Liaqat et al., 2016) stated that $2 \%$ supplementation of MOLP had best effects on the weight gain of the broilers as compared to the other supplementation of MOLP and control group of broilers. 4\% MOLP had positive effects in the weight of the broilers comparatively from the control group but not more than weight gain of 4\% MOLP. Furthermore, when soyabean was replaced with the MOLP, a significant decrease in the feed intake was observed with no significant effect on the weight gain of the broilers. They reported that this decrease in the feed intake was might be due to the non-palatability caused by MOLP of their experimental diets, however this trouble was not obvious in the current study. Another study caused by (Onu \& Aniebo, 2011) found the noticeable increase in the body weight of the broilers that were fed with the different doses of MOLP and they concluded that this increase in the weight gain of the broilers might be due to the high protein content in the MOLP.

In the current experiment, Heterophils count was recorded highest in the group of broilers supplemented with $0.15 \%$ MOLP and minimum Heterophils count was found in the control groups of the broilers. Lymphocytes count was found highest in the control group of the broilers and minimum Lymphocytes count was found in the group of broilers supplemented with $0.15 \%$ MOLP. Heterophils to Lymphocytes Ratio (H:L) was lowest in the control group of broilers and highest $\mathrm{H}: \mathrm{L}$ was recorded in the group of broilers supplemented with $0.15 \%$ MOLP. There was a significant difference $(p<0.05)$ found in the $H: L$ in all the selected group of broilers. This positive effect directly on the heterophils and lymphocytes and indirectly on the health status of broilers might be due to the presence of various phytochemicals and bioactive components such as trace metal ions, vitamins, alkaloids, carotenoids, polyphenols, fats, carbohydrates, and proteins in MOLP. These results 
were found similar with the results of (Liaqat et al., 2016) in which they found a significance difference in the Heterophils count, Lymphocytes count and H:L of the broilers. Hematology of the broilers shows alterations in the groups of broilers supplemented with the different levels of MOLP while the biochemistry of the serum shows not a significant effect of MOLP supplementation in the feed of the broilers. Another study conducted by (Makanjuola et al., 2014) stated that the red blood cell (RBC) count, packed cell volume (PCV), and levels of haemoglobin were not significant across the treatment groups, a numerical increase was observed in chickens on Moringa-treated diets. There was significant effect on the H:L of the broilers supplemented with different levels of the MOLP.

\section{CONCLUSION}

From the outcomes of the current study it was concluded that MOLP supplementation in feed had best effects on the productive performance of the broilers as compared to the other supplementations and control group of broilers. It was also concluded that MOLP had no effect on the mortality of the broilers.

\section{AUTHOR'S CONTRIBUTION}

Naqash Khalid conducted the research and contributed in the collection of data, laboratory analysis and write up of the research article. Syeda Faryal Sakhawat and Hajira Mehmood contributed in the data collection, laboratory work and data analysis. Malik Mohsin Ali, Riaz Ali and Yasir Amin contributed in the data collection and management of the research flock. Muhammad Ayaz supervised the research work, study designing, write-up of research article and helped at each step of the work.

\section{ACKNOWLEDGEMENTS}

This research study was a part of Annual Technical Research Program (ATRP) 2019-20 of Dr. Naqash Khalid, Research Officer, Poultry Research Institute Jaba, Mansehra. The authors highly acknowledge the Poultry Research Institute Jaba Mansehra, for provision of the chicks and other commodities to conduct the Research Study.

\section{REFERENCES}

-Abbas TE (2013). The use of Moringa oleifera in poultry diets. Turkish J. Vet. Anim. Sci. 37(5): 492-496. https://doi. org/10.3906/vet-1211-40

-Amber K, Khan KR, Shah AH, Farooq M, Lodhi MH, Shah GM (2019). A comprehensive survey of floristic diversity evaluating the role of institutional gardening in conservation of plant biodiversity. Int. J. Biosci. 14(3): 325-339. https:// doi.org/10.12692/ijb/14.3.325-339
- Banjo O (2012). Growth and performance as affected by inclusion of Moringa oleifera leaf meal in broiler chicks diet. Growth. 2(9): 35-38.

- Ceciliani F, Morales GÁ, De Matteis G, Grandoni F, Ferreira RF, Roccabianca P, Lecchi C (2020). Methods in isolation and characterization of bovine monocytes and macrophages. Methods. https://doi.org/10.1016/j.ymeth.2020.06.017

- David L, Vidanarachchi J, Samarasinghe K, Cyril H, Dematawewa C (2012). Effects of moringa based feed additives on the growth performance and carcass quality of broiler chicken.

- Fathallah S, Shawky S, Gaffer K, Hussein M, Zahran I (2020). Effect of some herbal extracts on growth performance and liver enzymes in broilers. Kafrelsheikh Vet. Med. J. 17(1): 28-31. https://doi.org/10.21608/kvmj.2020.39778.1006

- Gowrishankar R, Kumar M, Menon V, Divi SM, Saravanan M, Magudapathy P, Venkataramaniah K (2010). Trace element studies on Tinospora cordifolia (Menispermaceae), Ocimum sanctum (Lamiaceae), Moringa oleifera (Moringaceae), and Phyllanthus niruri (Euphorbiaceae) using PIXE. Biolog. Trace Element Res. 133(3): 357-363. https://doi. org/10.1007/s12011-009-8439-1

-Khan I, Zaneb H, Masood S, Yousaf M, Rehman H, Rehman H (2017). Effect of Moringa oleifera leaf powder supplementation on growth performance and intestinal morphology in broiler chickens. J. Anim. Physiol. Anim. Nutrit. 101: 114-121. https://doi.org/10.1111/jpn.12634

- Liaqat S, Mahmood S, Ahmad S, Kamran Z, Koutoulis K (2016). Replacement of canola meal with Moringa oleifera leaf powder affects performance and immune response in broilers. J. Appl. Poult. Res. 25(3): 352-358. https://doi. org/10.3382/japr/pfw018

- Makanjuola B, Obi O, Olorungbohunmi T, Morakinyo O, Oladele-Bukola M, Boladuro B (2014). Effect of Moringa oleifera leaf meal as a substitute for antibiotics on the performance and blood parameters of broiler chickens. Livest. Res. Rural Develop. 26(8): 144.

- Mbikay M (2012). Therapeutic potential of Moringa oleifera leaves in chronic hyperglycemia and dyslipidemia: a review. Front. Pharmacol. 3: 24. https://doi.org/10.3389/ fphar.2012.00024

- Nkukwana TT (2012). The Effect of Moringa Oleifera Leaf Meal on Growth Performance, Get Integrity, Bone Strength, Quality and Oxidative Stability of Meat from Broiler Chickens. University of Fort Hare.

- Nopiya N, Hindriana AF, Sulistyono S (2020). Students'science process skills and interpersonal intelligence in biology learning using guided inquiry. JPBI (Jurnal Pendidikan Biologi Indonesia).6(1): 123-134.https://doi.org/10.22219/ jpbi.v6i1.10634

- Olugbemi T, Mutayoba S, Lekule F (2010). Effect of Moringa (Moringa oleifera) inclusion in cassava based diets fed to broiler chickens. Int. J. Poult. Sci. 9(4): 363-367.

- Onu P, Aniebo A (2011). Influence of Moringa oleifera leaf meal on the performance and blood chemistry of starter broilers. Int. J. Food Agric. Vet. Sci. 1(1): 38-44. https://doi. org/10.3923/ijps.2010.363.367

- Ravindran V, Kornegay E, Cherry J (1983). Feeding values of cassava tuber and leaf meals. Nutr. Rep. Int. 28: 189-196.

- Teixeira EMB, Carvalho MRB, Neves VA, Silva MA, Arantes-Pereira L (2014). Chemical characteristics and fractionation of proteins from Moringa oleifera Lam. leaves. Food Chem. 147: 51-54. https://doi.org/10.1016/j. 
foodchem.2013.09.135

- Yang RY, Chang LC, Hsu JC, Weng BB, Palada MC, Chadha M, Levasseur V (2006). Nutritional and functional properties of Moringa leaves-From germplasm, to plant, to food, to health. Moringa leaves: Strategies, standards and markets for a better impact on nutrition in Africa. Moringanews, CDE, CTA, GFU. Paris. 